\title{
Incertidumbre, otredad, subalternidad: desafíos para la práctica, herramientas para la comprensión de la enseñanza de la historia
}

\section{Uncertainty, Otherness, Subordination: Challenges for Practicing and Tools for Understanding the Teaching of History}

\author{
Ana Zavala \\ Centro Latino Americano de Economía Humana, Montevideo, Uruguay \\ (D) orcid.org/0000-0001-6324-1344 \\ azavala@claeh.edu.uy
}

Resumen: Este artículo enfoca las relaciones entre la didáctica de la historia y las novedades de la filosofía de la historia contemporánea en lo referente a las herramientas de análisis que esta última puede proveer para la comprensión de la acción de enseñar historia. Siendo la pérdida de la certeza en relación con el conocimiento del pasado una de las consecuencias más visibles del contacto con la hermenéutica del siglo xx es necesario considerar los modos en que esto afecta a las perspectivas sobre la enseñanza de la historia-práctica, pero también proyecto político y social. Un breve recuento de los cambios más relevantes en la filosofía de la historia indicará los modos en que particularmente la incertidumbre, la otredad y la dimensión subalterna de muchos de los protagonistas cuyas vidas y peripecias estudiamos en clase pueden devenir en herramientas de análisis de la práctica de la enseñanza.

Palabras clave: filosofía de la historia contemporánea; didáctica de la historia; práctica de la enseñanza de la historia; herramientas de análisis. 
Abstract: This article focuses on the relationships between the teaching of history and the innovations in the philosophy of contemporary history, and in particular the analytical tools that the latter can provide to understand the teaching of history. Since the loss of certainty about knowledge of the past is one of the most visible consequences of the contact with 20th century hermeneutics, one must consider how this affects perspectives on the teaching of history -as a practice but also as a political and social project. A brief recap of key changes in the philosophy of history will indicate shows how uncertainty, otherness and the subordinate dimension of many of the protagonists, whose lives and experiences we study at school, can become tools for analyzing teaching practice.

Key words: philosophy of contemporary history; history teaching; history teaching practice; analytical tools.

Fecha de recepción: 10 de noviembre de 2016 Fecha de aceptación: 16 de febrero de 2017

\section{INTRODUCCIÓN: HERRAMIENTAS PARA PENSAR}

Podría ser que para hablar tanto de "la historia" -es decir, de la historio-
grafía- tal como la conocemos hoy en día y como se la desea enseñada en las aulas, no pudiéramos ir mucho más atrás de los comienzos del siglo xIX. Sería, sin embargo, difícil pensar que los historiadores hacen actualmente su trabajo como lo hacían en aquel momento. Debemos tener en cuenta que ha sido el siglo xx -entre la filosofía y la hermenéutica- el que ha abierto a los historiadores un mundo diferente en el cual las antiguas certezas y pretensiones de verdad han dejado lugar a maneras tal vez totalmente diferentes de ver, comprender y sobre todo escribir o hablar acerca del pasado.

Por otra parte, no resulta difícil de entender la dimensión problemática y por momentos conflictiva que esta situación plantea a las formas de concebir y proponer la enseñanza de la historia heredadas de un momento en el cual entremezclan sus orígenes los Estados-nación, la historia y los sistemas educativos "para todos". Este artículo da por sentada la existencia -en

${ }^{1}$ En trabajos anteriores he planteado la idea de que mientras que en "los comienzos" parece haber habido una suerte de "pacto fundacional" entre el Estado, la producción histo-

\section{()(1) $(2$}


el presente-de un escenario diversificado y fracturado en el cual interactúan de forma disonante un mandato social e institucional que tiene sentido en el eje de la certeza, unas novedades historiográficas, metodológicas y filosóficas que tienden a no coincidir con él en este aspecto, y finalmente unas prácticas reales de enseñanza que en su infinita diversidad permanecen opacas en lo esencial a las miradas de los otros -tanto más cuanto más generalizadoras intenten serlo-. Aunque sin duda agregaría una nota más a la disonancia, es de hacer notar que queda definitivamente por fuera del abordaje de este artículo la cuestión de qué es lo que "realmente" aprenden los estudiantes como efecto de sus contactos con la historia -la positivista, la marxista o la poscolonial- a través de los distintos dispositivos institucionales que los implican. En consecuencia, el artículo permanece ajeno a cualquier identificación mecánica entre lo enseñado y lo aprendido, y naturalmente a una dimensión permanente de esto último. De alguna manera debemos hacernos a la idea no sólo de la cuota de incertidumbre que rodea al conocimiento del pasado que enseñamos en clase, sino también de que nuestro propio conocimiento del presente no es menos incierto por el hecho de convivir con él.

Atenerse a la idea de que así como es incierto el pasado que estudian los historiadores, también lo es lo que podamos saber acerca de lo que sucede en las aulas en las que se enseña la historia (cuál historia, cómo, para qué...) o en la mente de los estudiantes contribuye a ver el escenario desde otro punto de vista. Nos invita por ejemplo a considerar el hecho de que hay herramientas de análisis que mantienen su pertinencia en relación con objetos de naturaleza bastante diferente como pueden ser los acontecimientos del pasado, el trabajo de los historiadores, la lectura de los textos antiguos, el discurso ${ }^{2}$ de los profesores y naturalmente las producciones estudiantiles habladas o escritas. En este trabajo me limitaré a considerar las herramientas provenientes de la filosofía de la historia contemporánea y seguramente no toda. Dejaré de lado por el momento las que podrían provenir de la lingüística, de la filosofía de la acción, de la psicología, en especial el psicoanálisis, e incluso de la sociología, aunque me parecen igualmente pertinentes. Este artículo parte precisamente de la base de que habiendo un espeso entretejido de prácticas

riográfica y la enseñanza de la historia, en la actualidad la coherencia entre los intereses de esos tres actores sociales parece difícil de demostrar. Véase Zavala $(2013,2014)$.

${ }^{2}$ Considerado en sentido amplio, implicando su proyecto de curso, el guión de cada clase, los textos hablados o escritos de su autoría -descontando toda la carga intertextual de los mismos-, así como propuestas de ejercitación y evaluación, entre muchas otras cosas que podrían ser tomadas en consideración.

\section{()(1) $\$$}


y de textos que configuran desde la lectura hasta la investigación y la enseñanza, incluyendo naturalmente la escritura (aun la estudiantil), es posible acercarse a cada una de ellas con las mismas herramientas. No se trata, sin embargo, de buscar o encontrar lo mismo, sino precisamente lo singular que le da a cada situación el hecho de no poder dejar de estar ligada a un sujeto de acción ya sea en el pasado lejano o cercano o en el presente inmediato.

El artículo constará entonces de dos partes. En la primera me ocuparé de repasar brevemente las principales novedades aportadas por la filosofía de la historia ${ }^{3}$ del último tercio del siglo xx en relación con la pérdida de las certezas y de homogeneidades, expandiéndome hasta el punto del cuestionamiento a la europeización/universalización de los grandes lineamientos del análisis no del pasado sino de los pasados de los habitantes de las distintas regiones de la tierra. Aunque a lo largo de este planteo iré anunciando su relación con algunos asuntos relativos a la enseñanza de la historia -proyecto político social y especialmente prácticas de aula-, será recién en la segunda parte que me abocaré de lleno a mirar la práctica de la enseñanza como un lugar de posibilidad, a veces avant la lettre, para activar el juego fugaz con lo incierto y lo otro, así como con la subalternidad esencial que ostentan la mayoría de los sujetos a cuyas vidas y peripecias dedicamos nuestras clases. Serán estas herramientas de análisis las que me permitirán ver el contenido de la clase a la vez como un texto y como lo que el presente del análisis dice de ese texto. El sentido que ese texto y esa acción tuvieron en su momento, son también parte de un pasado que el análisis de esa práctica -que es otra acción- reconfigura desde su propio presente. La conclusión no hará más que redondear la tesis del artículo, conjugando los grandes lineamientos de la filosofía de la historia heredada del siglo xx con las miradas posibles en torno al análisis de las prácticas de aula, pero no las de todos en general, sino la de cada uno en su singularidad más radical. Ha de quedar claro en todo caso que si el artículo es propositivo en algún nivel no lo es en el de la práctica de la enseñanza de la historia, sino en el de las posibilidades abiertas a sus modos de análisis.

3 Utilizaré la expresión "filosofía de la historia" en lugar de "teoría de la historia" en atención al sentido que ella tiene en los trabajos de Carr, Dray, Geraets, Ouellet y Watelet (1982), Danto (2007), Koselleck (2010), Ricœur (2003), entre otros. Me inclina a esta opción la atención que prestan estos autores al trabajo historiográfico como construcción de un sentido - definitivamente filosófico- para contener lo que puede considerarse una teoría de la historia en sí misma.

\section{()(1) $(2$}




\section{OTROS, AJENOS, INCIERTOS Y SUBALTERNOS...}

No hay hechos, solo interpretaciones.

Friedrich Nietzsche

En el breve espacio de este apartado me limitaré a señalar algunos momentos historiográficos y filosóficos que dan cuenta de un tipo de acercamiento al pasado que ha abandonado en mayor o menor medida la pretensión de certeza respecto de su objeto de estudio.

Posiblemente el "la historia jamás es segura" con el que Michel de Certeau (1970, p. 11) inaugura su estudio sobre las poseídas de Loudun en la Francia del siglo XVII pueda ser considerado casi como un gesto fundacional. Sin embargo, para ese momento la filosofía ya había recorrido un largo trecho en ese sentido. Las consideraciones heideggerianas -que aparecen una y otra vez en distintas miradas filosóficas al pasado- ya habían hecho de la situación hermenéutica (Heidegger, 2002, p. 30) un lugar del presente, del sujeto y de la intención, rompiendo radicalmente con los pilares fundamentales de la hermenéutica clásica. Al recorrer las páginas de La escritura de la historia (Certeau, 1993) uno se encuentra con más de una idea conmovedora, ${ }^{4}$ como por ejemplo que el trabajo de los historiadores conoce un límite no entre lo que se sabe y lo que se ignora, sino entre lo pensable y lo que no lo es (Certeau, 1993, p. 112); o que la escritura no depende tanto del pasado que ha de narrar y hacer comprensible como de las condiciones que su "lugar" de producción le imprime. Esta condición se extiende naturalmente a la forma en que ese "lugar" se impone tanto en relación con la práctica de la investigación como a la de la escritura. Podría remitir finalmente a la idea de "inversión escriturística" (Certeau, 1993, p. 110) para fundamentar la idea de que en de Certeau queda poco de un modo de hacer y entender la historia que probablemente fue el que conoció cuando era estudiante.

${ }^{4}$ Es a partir de la amplia gama de apoyos teóricos que respaldan su trabajo que, de la mano de Barthes, Foucault, Aron, e incluso Marx -entre muchos otros-vemos que iba definitivamente en el sentido de su tiempo.

\section{(ㅇ)(1) $\$$}


Casi simultáneamente Hayden White $(1978)^{5}$ publicaba un artículo con el sugestivo título de The historical text as a literary artifact ${ }^{6}$ retomando la idea ya planteada en Metahistory (White, 1973, pp. 1-4) de que la historiografía es un discurso y como tal ha de entenderse. Desde este punto de vista, su planteo no se aleja ni del de Michel de Certeau (1993) en La escritura de la historia, ni del de Roland Barthes (1987a) en "El discurso de la historia" en el sentido de diluir la oposición radical entre relato histórico (verdadero) y relato de ficción (imaginario y falso), entre hechos y acontecimientos históricos y los que no lo son (véase en particular Certeau, 2007). Las ideas de "ilusión referencial" mismo ponen de cabeza muchas ideas que acompañan algunas representaciones de lo que la historia -en el sentido de historiografía- es.

De alguna manera el "otro" de Michel de Certeau es también el de Carlo Ginzburg. En El queso y los gusanos, también contemporáneo de las obras mencionadas, Ginzburg (1994) se apropia de la noción gramsciana de "subalterno", dando cuenta de otra manera de la dificultad en acceder con certeza a algunos objetos de estudio del pasado, que desde cierto punto de vista podrían ser una inmensa cantidad. Tributario asimismo de los aportes bakhtinianos en relación con la dimensión polifónica de los discursos, la obra de

${ }^{5}$ La primera versión de L'opération historiographique, forma parte del primer tomo de Faire de l'histoire, compilado por J. LeGoff P. Nora, publicado en 1974.

${ }^{6}$ Originalmente publicado en 1974, en Clío -núm. 3-y compilado posteriormente en White, Tropics of discourse essays in cultural criticism, 1978, y en el mismo año en un libro con un título aún más sugestivo de The writing of history: literary form and historical understanding compilado por Robert H. Canary y Henry Kozicki. En un artículo publicado en 2008 bajo el título de The historical event, White (2008) mantiene su postura diciendo, por ejemplo: "The historical past exists only in the books and articles written by professional investigators of pasts and written for the most part for one another rather than for the general public. This historical past is, according to the doxa of the professionals, constructed as an end in itself, has very limited if any practical usefulness, and contributes only minimally to the understanding of what ordinary folk regard as 'the present'. It is ironic that, as professional historical studies have become more and more scientific, they have become less and less useful for any practical purpose, including the traditional one of educating the laity in the realities of political life" (pp. 10-11).

${ }^{7}$ Barthes (1987a, p. 168). Ricœur (2003, p. 315) va más allá, y un cuarto de siglo después habla de "pulsión referencial". "Así, la representación en cuanto narración no se dirige simplemente hacia las cosas acaecidas; la forma narrativa como tal interpone su complejidad y su capacidad propias en lo que a mí me gusta llamar pulsión referencial del relato histórico; la estructura narrativa tiende a formar círculo consigo misma y a excluir como fuera de texto, como presupuesto extralingüístico ilegítimo, el momento referencial de la narración" (cursivas mías).

\section{()(1) $\$$}


Ginzburg contribuye también a restar en el terreno de las certezas aunque en el fondo se lo pueda considerar metodológicamente optimista. ${ }^{8}$

Con miradas mucho más cercanas a la hermenéutica y al análisis del discurso, los enfoques de la historia conceptual (Begriffsgeschichte) y de la historia intelectual han contribuido al menos a hacer mucho más complejo -y de hecho incierto- el camino hacia la comprensión del pasado a través de los textos que nos vinculan a él. Tanto la adscripción fuertemente gadameriana -y heideggeriana- de Koselleck como la preferencia skinneriana por la lingüística pragmática de Austin y de Searle hacen de la historia conceptual y de la historia intelectual modos interpretativos del pasado en los cuales la clave está en un intento a veces desesperado de vencer esa extrañeza esencial que lo caracteriza. ${ }^{9}$

Historia de las ideas o historia de los conceptos, ambas corrientes a menudo tenidas por opuestas hacen foco cada una a su manera en la cuestión del lenguaje. Asumiendo la impronta de una distancia temporal imposible de acortar parten de la base de que lo que ahora leemos en los textos de otras épocas significaba tal vez -más bien seguramente- otra cosa para quienes escribieron con esas mismas palabras que podemos hacerlo nosotros hoy en día. ${ }^{10}$ De una manera o de otra, para todos estos autores y corrientes la idea

${ }^{8}$ Me refiero, por ejemplo, a afirmaciones de este tipo: "Si las pretensiones de conocimiento sistemático aparecen cada vez más veleidosas, no por eso se debe abandonar la idea de totalidad. Al contrario. La existencia de un nexo profundo, que explica los fenómenos superficiales, debe ser recalcada en el momento mismo en que se afirma que un conocimiento directo de ese nexo no resulta posible. Si la realidad es impenetrable, existen zonas privilegiadas - pruebas, indicios- que permiten descifrarla" (Guinzburg, 1994, p. 219).

${ }_{9}$ Ricœur (2003, pp. 457 y ss.) habla de la paseidad del pasado histórico en términos de su "condición histórica".

${ }^{10}$ En este sentido, Koselleck (1993) sostiene: "Es claro que el sentido exacto sólo se puede desprender del contexto de todo el Memorándum, pero también hay que deducirlo de la situación del autor y de los destinatarios, además de que habrán de considerarse la situación política y las circunstancias generales de la Prusia de entonces, así como, finalmente, habrá de comprenderse el uso lingüístico del autor, de sus contemporáneos y de la generación que le precedió, con los que participaba en una comunidad lingüística." (p. 107). Mientras que por su parte Skinner (2000) afirma: "La fórmula apropiada y famosa -famosa para los filósofos, al menos-es, más bien, que no debemos estudiar los significados de las palabras, sino su uso. Puesto que en este sentido no puede decirse, en última instancia, que la idea dada tenga ningún significado que pueda asumir la forma de un conjunto de palabras que, a continuación, sea posible deducir cuidadosamente y rastrear a lo largo del tiempo. Antes bien, el significado de la idea debe ser sus usos para referir de diversas maneras" (p. 178). En este texto hay una referencia a las Investigaciones filosóficas de Wittgenstein (1999, p. 43): "el significado de una palabra es su uso en el lenguaje", que bien podría haber estado también en el de Koselleck (1993) reproducido en esta misma nota.

\section{(ㅇ)(1) $\$$}


de que el pasado puede ser simplemente conocido a través de sus huellas -especialmente las escritas- va perdiendo vigencia en favor de la explicitación de un trabajo de interpretación que es sin duda un trabajo de autor, pero también un trabajo del tiempo y del lugar. Acompaña este gesto la idea de que la herramienta de análisis no es neutral sino más bien ideológica, y que la relación entre ella y los resultados obtenidos (conceptualizaciones, entrelazamientos causales, incluso la propia organización del relato "fáctico") puede ser puesta en palabras de la misma manera que los términos de la historia relatada pueden serlo.

Cuando uno trata de rastrear -no en el sentido que Skinner (2000, p. 155) reprocha a Lovejoy- los lazos, las deudas, las fidelidades que están detrás de todo este movimiento renovador, necesariamente hay que transitar por el terreno de la filosofía. Es en este sentido que varios autores (Donnelly, 1999; Grondin, 2003; Petit, 2014) reconocen en la figura de Heidegger un punto de inflexión ineludible en la refundación hermenéutica del siglo xx. En ocasión de un análisis sobre la obra de Aristóteles ${ }^{11}$-que fue tema de un curso en 1922- Heidegger (2002) planteó la idea de "situación hermenéutica" que separa claramente el presente del lector del pasado lejano, a veces lejanísimo, del autor: "La situación de la interpretación, en cuanto apropiación comprensiva del pasado, es siempre la situación de un presente viviente" y continúa: "El pasado sólo se manifiesta con arreglo a la resolución y a la capacidad de apertura de la que dispone el presente" (p. 30) para concluir que es precisamente la explicitación de las herramientas de análisis lo que hace valiosa una interpretación, en tanto tal porque es "la condición fundamental que permite dar expresión al pasado en general". De hecho, Heidegger articula -siguiendo a Nietzsche- el presente con el pasado y el futuro tanto en la situación hermenéutica como en el acontecer de la vida misma. ${ }^{12}$

${ }_{11}$ Publicado muy tardíamente en el siglo xx, luego de la muerte de Heidegger con el título original del curso: "Interpretaciones fenomenológicas sobre Aristóteles" y que se conoce como el Informe Natorp. Recoge el contenido de distintas versiones mecanografiadas, para la interpretación de las cuales se recurrió, cuando fue posible, al testimonio de los que habían sido sus alumnos en el curso. La edición alemana (que es la que está traducida al francés) está por ejemplo, prologada por Gadamer, en su calidad de alumno del curso. No es el caso de la edición en español.

${ }^{12}$ En realidad su "hermenéutica" deja de limitarse al texto para concentrarse en la existencia. Véase Heidegger (2000). A diferencia de Agustín, al menos en el análisis que hace Ricœur (2004) en Tiempo y narración I, la preocupación de Heidegger no es la naturaleza del tiempo, sino la temporalización de la comprensión. Sin embargo, los conceptos de "presente del pasado", "presente del presente" y "presente del futuro" podrían -siguiendo a Ricœurtambién articularse hermenéuticamente en tanto "aporías del tiempo".

\section{()(1) $\$$}


Es en esta misma línea que Gadamer (1977, pp. 331 y ss.) habla de un "círculo hermenéutico" ${ }^{13}$ que da cuenta de la temporalidad e inestabilidad de la comprensión ("Comprender es siempre hacerlo de otra manera") (p. 367) así como de la participación activa del lector en la comprensión/interpretación de un texto en dos registros: el de la "fusión de horizontes" (el del autor y el del lector) y el de la "aplicación" (lo que la lectura significa para el lector y lo que luego hace a partir de allí). Al igual que la huella de Heidegger se percibe en su antiguo alumno Gadamer, la de este último es también visible en Koselleck, ${ }^{14}$ su alumno de toda la vida. Es así que vemos la manera en que Koselleck (1993, pp. 333-357) articula a través de la experiencia del lenguaje un juego entre un "espacio de experiencia" y un "horizonte de expectativa" que cuentan tanto para los actores del pasado que produjeron los textos que llegan hasta el presente, como para el historiador que los está leyendo.

La idea de que en materia de interpretación -y esto vale especialmente para los textos de los que los historiadores se sirven- nada está dicho, y si está dicho lo primero que hay que hacer es sospechar de eso y poner los ojos en la forma en que esa interpretación heredada ha sido concebida tiene todo para ser considerada como heideggeriana (véase Heidegger, 2002, pp. 51-52). Encontramos naturalmente sus huellas en Derrida (quien pasa de la Destruktion a la déconstruction conservando en grandes líneas el sentido original), en Spivak, en Gadamer y en Koselleck, además de en muchos otros (como Ricœur, por ejemplo). Hay que admitir, sin embargo, que las miradas tanto de la historia conceptual como de la historia intelectual tienen un horizonte estrictamente europeo, y tal vez sólo alemán, inglés y hasta cierto punto francés o italiano.

En este sentido, tanto los estudios de la subalternidad como las miradas poscoloniales representan un esfuerzo deconstructivo que va más allá del trabajo hermenéutico e interpretativo respecto de los textos antiguos. De hecho, lo que ponen en tela de juicio - entre otras cosas- es la universalidad de la historia universal ${ }^{15}$ tanto desde el relato como desde las categorías con-

${ }^{13}$ Gadamer toma de Heidegger en Ser y tiempo la expresión "círculo hermenéutico", pero que no tiene para ambos autores exactamente la misma connotación. Me excuso de explicitar más en detalle la cuestión en la medida en que no la encuentro relevante para el planteamiento de este trabajo.

${ }^{14}$ Que también fue alumno de Heidegger en Bristol, universidad a la que asistía al mismo tiempo que a Heidelberg (1947-1953).

15 Tomando un par de ejemplos, entre muchos posibles, consignaré por ejemplo que Chakrabarty (2007, p. 3) habla de "provincializar Europa" en el sentido de darle un lugar regional del mismo estatus que pueden tener América, África o las distintas regiones de Asia.

\section{()(1) $\$$}


ceptuales con las cuales la historia se ha acercado al pasado al menos a partir de la modernidad. A los efectos de este trabajo interesa por lo tanto destacar el aporte de estas posturas en la disolución de las certezas que la historiografía -la europea y la que fuera de Europa seguía sus lineamientos- había heredado principalmente del xix. Si Michel de Certeau o Carlo Ginzburg nos habían enfrentado a la evidencia de la otredad del pasado, a la dificultad de volver pensable lo impensable; si Reinhart Koselleck y Quentin Skinner nos habían hecho dudar de lecturas demasiado técnicas, demasiado obvias o demasiado seguras de los textos heredados del pasado, la idea de que hay otros modos no sólo de interpretar sino de conocer el pasado de los subalternos ${ }^{16}$ - de esos subalternos discursivamente construidos en buena medida por la historiografía occidental- amplía en forma exponencial la dimensión incierta no sólo del pasado sino de lo que se ha dicho en relación a él anteriormente.

La idea de que los subalternos no pueden hablar en la historiografía (Spivak, 1998) quebranta fuertemente la confianza que se pueda tener no sólo en lo que refiere a los otros lejanos en el sentido de los no europeos, sino también -como en los planteamoentos de Ginzburg y de Certeau- en lo que se ha dicho de los campesinos, de las mujeres, de los niños, de los locos, y de todos aquellos que siempre "son dichos" tanto en las fuentes de los historiadores como en sus propios textos. Sin ningún optimismo y prácticamente cerrando las puertas Spivak (2008, pp. 36 y ss.) proclama que la conciencia del otro es irreductible y termina configurándolo como el tout-autre derrideano (Derrida, 1967, p. 69; Spivak, 1998, p. 208). Es importante, sin embargo, tener en cuenta que estas nuevas miradas no surgen de la nada o al azar en algún momento determinado. Ha sido con seguridad el escenario inaugurado por la ruptura del viejo orden colonial heredado del siglo xix lo que en opinión

\footnotetext{
"PROVINCIALIZING EUROPE is not a book about the region of the world we call 'Europe'. That Europe, one could say, has already been provincialized by history itself. Historians have long acknowledged that the so-called 'European age' in modern history began to yield place to other regional and global configurations toward the middle of the twentieth century. European history is no longer seen as embodying anything like a "universal human history'." Por su parte, Mignolo (2005, p. 9) habla de las localizaciones epistemológicas del conocimiento, en particular el histórico. "Pensar en la organicidad entre lengua, cultura y territorio sería sólo posible dentro de la epistemología colonial/moderna, que separó el espacio del tiempo, fijó las culturas a territorios y las localizó atrás en el tiempo de la ascendente historia universal de la cual la cultura europea (también fija a un territorio) era el punto de llegada y de guía para el futuro."

${ }^{16}$ Algunos autores como J. Pouchepadas (2000) intentan ver en la historia desde abajo un cierto paralelo con la subalternidad... desde mi punto de vista no hacen más que reafirmar la subalternización de "los de abajo".
}

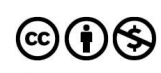


de muchos habilitó la emergencia de nuevas formas de mirar el pasado de las antiguas colonias... con herramientas tomadas de un pensamiento europeo convulsionado y renovado por su propia dinámica interna mucho más que por "las catástrofes", como les llama Hobsbawm. Es posiblemente esta situación la que ha permitido a Walter Mignolo hablar de "epistemologías fronterizas", en el sentido de la articulación de la herencia colonial europea -que es innegable-y las formas epistemológicas propias de los distintos locus de enunciación del conocimiento científico, técnico, histórico... También han permitido a Mario Rufer (2009), hablar de "huellas errantes", o a Florencia Mallon (2003) de "patriarcado democrático".

A pesar de lo extremadamente sintético de la presentación de esta cuestión, no tendría que quedar duda en relación a la profundidad de los cambios que se han presentado en la historiografía y en la filosofía de la historia en las últimas décadas. Es cierto que de alguna forma esto ha afectado la selección temática de los autores que han optado por abordar asuntos antes impensados para la historiografía. También es cierto que muchas veces las nuevas temáticas no han significado cambios profundos en los modos de "hacer historia" (o de enseñarla).

Si sólo ponemos los ojos en las diversas maneras en que términos sólidamente asentados en la historiografía como nación y Estado (y también Estado-nación $)^{17}$ han sido repensados y reconceptualizados nos podemos hacer cargo del desafío que significa para la enseñanza de la historia institucionalizada acercarse a este mundo nuevo e inesperadamente renovador al mismo tiempo que cuestionador. Ahora más que nunca la historia es un asunto del presente, del tiempo y del sujeto o de la fracción de la sociedad que se hace preguntas y busca respuestas en el estudio del pasado. Los historiadores, las corrientes, las ideologías, las posturas metodológicas han dejado de ser transparentes para ser - precisamente- la clave de la comprensión de los textos historiográficos en los cuales se basa la enseñanza de la historia. No en vano el debate en torno a la pregunta siempre actualizada "¿qué his-

${ }^{17}$ Ineludibles en este sentido los trabajos de Prasenhit Duara, Historicizing national identity, or who imagines what and when (1995); Partha Chatterjee, The nation and its fragments. Colonial and postcolonial histories (1993); La nación en tiempo heterogéneo (2007), o La política de los gobernados (2004), y Stathis Gourgouris, Dream nation. Enlightement, colonization and the institution of modern Greece (1996). Para el ámbito latinoamericano, deudor en cierta forma del impulso inicial de los autores surasiáticos, pueden verse los trabajos de: Mario Rufer, $\mathrm{La}$ temporalidad como política: nación, formas de pasado y perspectivas poscoloniales (2010); Mónica Quijada, El paradigma de la homogeneidad (2000), y Walter Mignolo, Herencias coloniales y teorías postcoloniales (1996), entre muchísimos otros.

\section{()(1) $\$$}


toria enseñar?" se ha vuelto más duro que nunca. Si durante un siglo o posiblemente más la cuestión apuntó a la mejor forma de ajustar unos medios (es decir los contenidos y para algunos también las formas de enseñarlos) a unos fines que parecían definitivos e incuestionables en relación con la identidad nacional, con el sentido del tiempo presente o con la formación de una conciencia histórica en los estudiantes, hoy en día lo que es necesario repensar son - precisamente- los fines a los que sirve la enseñanza no de la historia sino de cuál historia, en el sentido de cuál historiografía -y por añadidura, de cuál filosofía de la historia.

El apartado siguiente, lejos de constituir una postura militante a favor de la inclusión de temáticas o posturas historiográficas o filosóficas en los cursos de historia a nivel secundaria, constituye más bien un intento por transformar las novedades de la historiografía y de la filosofía de la historia recientes en herramientas de análisis de la práctica de la enseñanza, no en general sino siempre en primera persona del singular. No ha de esperarse de él pues sugerencias o propuestas relativas a qué enseñar o cómo hacerlo en clase de historia. Las referencias al mundo de las prácticas apuntarán más bien a mostrar la pertinencia de una herramienta que unas conclusiones derivadas de su uso.

\section{...EN NUESTRAS AULAS \\ El pasado es un país extraño: allí las cosas se hacen de otra manera.}

David Lowenthal (1993)

No hay forma de no pensar que cuando se decidió crear una asignatura escolar llamada "historia" su enseñanza estaba ligada a unas expectativas que combinaban de una manera singular la adquisición de conocimientos con la adopción de conductas y valores altamente deseados tanto desde la esfera política como desde la social. La revolución francesa lo bautizó con el nombre de catecismo republicano, ${ }^{18}$ idea que permaneció vinculada a los fines de la enseñanza de la historia posiblemente hasta bien entrado el siglo xx tanto en Francia como en el resto del mundo liberal euroamericano. De hecho existe actualmente una extensa bibliografía en varios idiomas ligada a los fines cí-

\footnotetext{
${ }^{18}$ Véase Lachabeaussière (n. d.).
}

\section{(ㅇ)(1) $\$$}


vicos de la enseñanza de la historia -que de alguna manera complementa o toma el relevo de los fines patrióticos (véase Laville, 2000) - y a la idea de la formación de una conciencia histórica ${ }^{19}$ que nos permite asumir la idea de una fuerte perduración de algunos postulados fundacionales en este asunto.

En este escenario se combinaban distintos niveles de certezas, a saber, la relativa al conocimiento del pasado que suministraba la historiografía y naturalmente la posibilidad de que los conocimientos enseñados fueran -al decir de Ricœur (1996, p. 840) - "numéricamente idénticos" no sólo al contenido de los libros de historia sino también al de lo que todos (es decir, cada uno de) los alumnos "aprendían", asumiendo/deseando que era/fuera de una vez y para siempre.

Lo interesante a mi manera de ver es que al mismo tiempo que de la mano de la filosofía y de la hermenéutica las certezas respecto de lo que "sabemos" acerca del pasado han tendido a abandonarnos, esas herramientas nos permiten introducirnos en un mundo -disperso en el tiempo y en el espacio, y por cierto diverso- en el que todos son intérpretes, ya sea en la producción de textos respecto de su experiencia, ya sea respecto del contenido de otros textos a los que han accedido por la lectura. En lo que nos interesa aquí, este mundo incluye además de los historiadores (que leen y escriben, y en ocasiones también hablan sobre lo que han leído y sobre lo que piensan) a los profesores de historia (que leen, hablan y a veces también escriben sobre lo que han leído y en particular, sobre lo que saben y piensan acerca de lo que saben) y a los alumnos (que escuchan, leen, hablan y escriben sobre lo que leyeron y escucharon). En el mismo gesto, así como tenemos que asumir que lo que los historiadores dicen del pasado constituye básicamente su mirada respecto de ese asunto, tenemos que hacernos cargo del hecho de que es igualmente complejo acercarse -aun desde una estricta contemporaneidada lo que sucede "realmente" en las aulas, las de historia y no sólo en ellas. No es que sea un mundo incomprensible, es simplemente que -tal como sucede con el pasado- su comprensión está mediada por la condición de autor de quien se ha acercado a un objeto de estudio que admite muchas lecturas y que -en este caso particular- es bastante más opaco de lo que muchos quisieran. Lo es no sólo en función de su extraordinaria diversidad sino también en función de la dificultad -bastante frecuente- de hacerse cargo de la fuerza ilocutoria de la que están dotados los testimonios acerca de lo que ha "realmente" pasado al interior de esas cuatro paredes.

19 Entre muchos, Rüsen (1989).

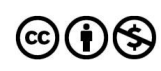


Es en función de estas consideraciones que este trabajo se limita a la oferta de herramientas de análisis en relación a lo que cada uno -en su momento y por sus razones- busca entender lo que ha hecho o ha sucedido en su clase, aun cuando podría intentar ofrecer una versión de lo sucedido una vez en un aula... Queda además sobreentendido que estas herramientas no implican la presencia de un tipo de historiografía, una cierta selección de contenidos o una forma particular de enseñar historia. ${ }^{20}$ Veamos entonces cómo algunas de las novedades ofrecidas por la historiografía y sobre todo por la filosofía de la historia contemporánea pueden convertirse en herramientas de análisis para entender las prácticas de enseñanza de la historia. En lo que sigue esbozaré algunas posibilidades que no son más que eso, posibilidades de expandir el potencial analítico de unas ciertas conceptualizaciones originalmente pensadas para entender la acción humana del pasado hacia un mundo habitado por el propio sujeto de acción y de análisis. Esto es posible, a mi manera de ver, porque estas no son herramientas para tratar de comprender sólo el pasado, sino que en el mismo gesto abarcan la tarea misma de la comprensión.

\section{Enunciación, objetividad, autoría}

Existe sin duda -y por cierto es saludable- una tendencia a dar por hecho que en clase de historia "la historia parece contarse sola", parafraseando a Barthes (1987a, p. 178). Para los estudiantes eso le da sentido a lo que hay que aprender -apropiarse de un objeto-texto- además de organizar un esquema de roles apropiado al mundo educativo. Esa historia que parece "contarse sola" -al no tener signos del emisor- parece a la vez objetiva y verdadera: el relato y lo relatado se convierten en "lo mismo" (Ricœur, 1996, pp. 840846). El uso del modo indicativo - tanto para autores, como para profesores y alumnos- es el que contribuye a convertir en cierta forma en "real" algo que ha dejado de serlo tal vez hace siglos o milenios. Posiblemente no terminemos nunca de destejer los cruces paradojales de un discurso en el que lo certero, lo

${ }^{20}$ Existe en este sentido una amplia bibliografía -en varios idiomas- que asocia las mejoras y los cambios en el terreno de la enseñanza de la historia a la superación de ciertos modelos historiográficos, en particular los nacionalistas y los positivistas. Este artículo asume que las herramientas de análisis son igualmente muy o poco potentes tanto si una clase de historia ostenta una mirada positivista como si se apoya en una historiografía nacionalista, marxista o poscolonial del tema que es objeto de enseñanza en ese momento.

\section{()(1)(3)}


posible, lo probable, lo hipotético y lo correcto a los efectos de este ámbito de discurso se combinan a veces de formas sensatas y a veces no tanto.

Estas consideraciones valen también para algunos modos de referir tanto a una postura historiográfica como al debate entre dos de ellas respecto de una cierta temática presentada en clase. Desde mi punto de vista es posible "leer" esta opción como un intento de borrar la voz del profesor que se traslada a la del historiador lo que en cierta forma apunta a la recuperación de un nivel de certeza respecto de lo que pasó "realmente". Esto depende, naturalmente, del nivel de énfasis que cada quien haga en relación a la historiografía como texto de autor y no como correlato necesario y fiel de la "realidad" del pasado. Por otra parte, el cotejo de posturas historiográficas -no siempre alentado ni necesariamente convertido en contenido razonable de enseñanza- tiene la virtud de tender a desplazar el eje de la clase o del curso hacia lo incierto no por la incertidumbre en sí misma, sino por la presencia de un desacuerdo no saldado a favor de ninguno de los contrincantes. Podría ser sin embargo el caso que las posturas estuvieran polarizadas en el sentido de lo correcto y lo incorrecto, es decir, de lo bueno y lo malo e incluso de lo verdadero y lo falso. La demanda de los estudiantes en busca de saber cuál de todos "tiene razón", al menos según el criterio del profesor, entrelazaría en esa situación la necesidad de certeza que se une a la idea de "saber" con la sacralización en cierto sentido de la relación del profesor con el saber que lo vuelve a la vez autoridad y punto de referencia más allá de otras consideraciones posibles. Podemos argumentar que sin duda hay algo de similar en la relación de los profesores con los textos de los historiadores en cuyas producciones se basan sus clases. Nada que Heidegger (2000) o Gadamer (1977, pp. 331 y ss.) no nos hayan hecho notar anteriormente.

De todas formas, para muchas personas -ya sea que estén a cargo de las aulas o de la planificación de los contenidos de enseñanza a nivel político- la falta de certeza es tenida casi por definición por lo que no se puede enseñar, por imposible y por inconveniente. Desde este punto de vista no hay como negar el hecho de que la brecha entre la historiografía o la filosofía de la historia actual y el mundo educativo existe y no parece tener perspectivas de cerrarse. Aun así, en un intento por combatir la incomodidad de la pregunta: Si "la historia nunca es segura", entonces iqué enseñamos?, la historia enseñada -que puede distar bastante de la historia sabida por el profesor (que a su vez puede distar un tanto de la historiografía leída) - acaba en muchos casos sintiéndose verdadera y objetiva. Por razones de muy distinto orden el mundo de las prácticas termina por recurrir a un gesto análogo al

\section{(이요 $\$$}


de la historiografía sin importar especialmente su postura metodológica, ideológica o filosófica.

\section{Habitar los límites}

Sabemos, sin embargo, que existen algunas brechas interesantes por las cuales en el mundo de las aulas se cuela a menudo la relatividad de las certezas que podemos tener respecto del pasado que estamos enseñando. En mi experiencia como profesora de historia y como acompañante de profesores en formación, he podido ver que muchas veces estos afloramientos tienen mucho más que ver con la interacción verbal espontánea que con la intención premeditada y planificada del profesor. Me refiero en particular a esas preguntas del tipo de: ¿y qué pasaba si el Faraón no tenía una hermana? o ¿cómo hacían cuando no tenían...? o incluso ¿por qué no querían...? Responder esas preguntas implica necesariamente admitir que no lo sabemos y que tal vez de hecho no haya forma de saberlo. Es interesante tener en cuenta que quienes las plantean esperan una respuesta a esas preguntas, una respuesta cierta y verdadera, y por lo tanto muchas veces trasladan a su profesor -tenido al instante por poco informado en la materia- la dificultad para responderlas de la manera que esperaban. Las fronteras entre "no lo sé", "nadie lo sabe" y "no hay forma de saberlo" no parecen tener mucho que ver con un escenario educativo en el que, precisamente, se espera que los alumnos aprendan lo que sus profesores les enseñan... porque lo saben. Enseñar acerca de estos límites es siempre un desafío enorme y toparse con ellos -inesperadamente- lo es todavía más.

Es un hecho, sin embargo, que la mayoría del discurso historiográfico -contemporáneo o no- se mueve más en torno al modo indicativo que al condicional. Es posible entonces que sea el manual, el libro de historia o la voz del profesor quienes encuentren la manera de no [querer] dejar lugar a dudas respecto del pasado. Para Michel de Certeau (1993, pp. 50-51) es la posibilidad de volver pensable al otro, que fascina justamente por su condición de otro, a través de la escritura de la historia -y también de su enseñanza aunque este aspecto seguramente no era 'pensable' para De Certeau- la que invita a decir las cosas como si hubieran pasado de esa manera. ${ }^{21} \mathrm{Y}$ esto vale tanto para el libro de historia, la clase de historia o la tarea domiciliaria de Juan.

${ }^{21}$ Véase Barthes (1987a y 1987b), artículos con los cuales el Michel de Certeau (1993) de La escritura de la historia se identifica ampliamente.

\section{()(1) $(9$}


Tal vez sea esa vocecita que pregunta ¿cómo lo saben? la que abra la puerta no a lo que no se conoce, sino a la explicitación del trayecto entre los eventos, los documentos y el trabajo interpretativo del historiador en el cual el profesor ha basado su clase. Tal vez es también el lugar por el que emerge la relación del profesor con ese saber que está enseñando, con los libros en los que lo leyó o con la forma en que se lo enseñaron cuando era estudiante. Al responder la pregunta a veces se nos escapa -barthesianamente hablando- (Barthes, 1987a, pp. 164 y 168) algo así como que ese historiador o los historiadores imaginan que... o suponen que si pasaba tal cosa... entonces se puede pensar que tal otra... Los límites confusos que separan o acercan verbos como creer, saber, imaginar, deducir, suponer y "saber" (en el sentido de tener certez $a^{22}$ ) dan cuenta seguramente de un modo de presencia en algunas aulas de lo incierto de la historiografía que a fin de cuentas no es más que un texto organizando la comprensión de su autor respecto de los eventos del pasado que le ocupan. Para los alumnos es en general una mala noticia oír decir que lo que sabemos es tan sólo lo que dicen los libros -lo cual no es necesariamente lo que pasó... en el sentido en que los protagonistas lo hubieran entendido-. En mi experiencia y en la de muchos colegas es este tipo de circunstancias el que habilita la posibilidad de aludir a la condición subalterna que revisten la mayoría de nuestros protagonistas dejando abierta la puerta a la existencia de otras miradas respecto del asunto.

\section{Nosotros, antes...}

En temas relacionados con la condición colonial o su superación la referencia a los lugares de enunciación (véase Mignolo, 2005) del discurso sobre el otro y sobre el pasado a estas alturas parece algo progresivamente ineludible. La naturalización de la dimensión eurocentrista de la mayoría de la historiografía que manejamos, aun la referida a asuntos no necesariamente europeos, es muy a menudo una pesada carga para ser percibida, y también para ser explicitada o abandonada como contenido de enseñanza.

Así como la incertidumbre es capaz de aparecer y de ser percibida a partir de unas ciertas herramientas de análisis, las dimensiones otra del pasado y subalterna de muchos de cuyas vidas nos ocupamos en clase emergen

${ }^{22}$ Imposible no pensar en esa provocativa aserción wittgensteiniana, según la cual, "lo que yo sé, lo creo" (Wittgenstein, 1999, p. 177).

\section{(ㅇ)(1) $(2$}


habitualmente en la espontaneidad de las interacciones orales. Creo que uno nunca acabará de sorprender a los estudiantes llevando la cuenta de "lo que no había" en cualquier momento del pasado que uno se sitúe, aun en las últimas décadas del siglo xx. No había Internet, no había vacunas, no había un plato para cada uno, no había pañuelos, no había vacaciones, no había remedios ni médicos... Es cierto que no siempre tomamos conciencia de que a veces asuntos que la bibliografía sobre una cierta época no aborda en profundidad terminan siendo el eje de la comprensión de un tema que puede estar en clave económica -o incluso política- en el devenir de una clase para nada especial, porque la interacción con los alumnos tiene otras claves que la interacción con los lectores de un libro de historia.

Si la historia conceptual y la historia intelectual están cada una a su manera obsesionadas con el fantasma del anacronismo interpretativo -que es como la otra cara de la otredad del pasado- los profesores de historia podríamos estarlo doblemente. Pensemos por ejemplo -y siempre es una experiencia reconfortante (porque da cuenta de un vínculo fuerte) y desafiante (porque eso nunca está planificado) - en esos momentos en los que emerge alguna voz que pone armas de fuego en manos de los griegos antiguos o azúcar (o chocolate, o café) en la leche medieval, o incluso imagina campesinos decimonónicos leyendo (libros) y escribiendo (con lápiz y papel) de forma espontánea y natural. Despejar estos anacronismos -la mayor parte de las veces con base en una mezcla de conocimientos generales y de sentido común- es hacer del pasado un otro de nosotros fundamentalmente porque no dejamos de estar en el presente en que estamos para entender que ellos eran otros. De hecho podríamos pensar que se trata ante todo de anacronismos representacionales en los cuales las imágenes del presente (y a veces también los valores) generan en los estudiantes un telón de fondo delante del cual actúan los griegos, los romanos, los vikingos, Cristóbal Colón o Napoleón. ${ }^{23}$ De hecho, tratar de acceder a ese telón de fondo - uno y singular para cada cual- es como intentar acceder a la conciencia de los subalternos, esa que para Spivak (2008, pp. 41-42) es precisamente irreductible. Podemos saber que existe una dimensión representacional del pasado en la mente de todos nues-

${ }^{23}$ Hace unos años, luego de haber narrado lo esencial de la épica homérica de la Odisea solicité a los estudiantes (de primer año liceal) que trajeran por escrito su versión de mi relato. Recuerdo todavía un trabajo de varias páginas, ilustrado, que se titulaba: "La Odisea, una historia de guerra y de amor", cuyo eje central era la marcha hacia el feliz reencuentro de la pareja (el último capítulo se titulaba: "Al fin juntos").

\section{()(1) $(2$}


tros alumnos, pero difícilmente podemos saber exactamente cómo es en la mente de cada uno de los que interactúa con nosotros en una clase.

Por otro lado, hacerse cargo de los anacronismos interpretativos que pueblan nuestros propios discursos, a veces los de los libros en los que leímos, y a menudo el del manual en el que los alumnos estudian, es ya un esfuerzo de análisis de otro porte. Como siempre, el flanco más débil es el de la adjetivación "nacional", que nos hace saber de la existencia de charrúas uruguayos, de incas peruanos, de galos franceses, de una Latinoamérica colonial, y otras cosas por el estilo, como por ejemplo filósofos alemanes del siglo XVIII o españoles peleando contra los moros durante la reconquista. Pero también nos horrorizamos de situaciones relacionadas por ejemplo con niños o con mujeres, como si siempre la infancia o la mujer hubieran tenido -para todos, no sólo para ellos mismos-el mismo sentido que tienen entre nosotros (o que queremos que tenga para nuestros alumnos).

Todos sabemos que esto pasa en las clases, en los manuales y en los libros de historia. Sin embargo, es el mundo de las aulas el que hace, en general, que veamos los anacronismos interpretativos de los estudiantes más como una dificultad para comprender (correctamente) que como una conclusión metodológicamente frágil o directamente como un error. Siempre está ese alumno que pregunta: "Profe, ¿los campesinos no se daban cuenta que los sacerdotes los engañaban?”, como si la racionalidad científica que gobierna nuestro entendimiento de los fenómenos naturales fuera tan antigua como el mundo y hubiera estado siempre al alcance de todos.

\section{La misma palabra...}

Más allá de la otredad material del pasado está la cuestión del uso de las palabras cuyo sentido en el pasado puede no haber sido el mismo que en el presente. La historia conceptual nos ha mostrado que muchos términos -sobre todo relacionados con el accionar político y social-tienen su propia historia y que por lo tanto en el pasado no se usaban de la misma manera que nosotros los entendemos en la actualidad. Es el caso de república, democracia, revolución, sociedad, Estado, nación y tantas otras, incluyendo libertad, derecho (en particular lo que hoy llamamos derechos humanos) o sociedad. Pensando más en las ideas que en los conceptos propiamente dichos, la historia intelectual skinneriana debatió largamente con los textualistas -seguidores en el fondo de las líneas clásicas de la hermenéutica- optando finalmente por

\section{()(1) $(3$}


valorizar el aporte del contexto social, histórico, cultural, etc. ${ }^{24}$ Sin embargo -y por eso lo traigo a colación- para muchos historiadores que se sienten afines a esta postura la cuestión del contexto sigue siendo la clave principal del asunto. Hay por supuesto una vulgata intelectualista o conceptualista a nivel de la didáctica para la cual el recurso a "en aquella época" constituye una buena clave interpretativa -desde mi punto de vista, más bien informativapara acercarse a la "realidad" del pasado.

En comparación con los historiadores que escriben para un público que no conocen y que asumen que está en condiciones de comprender su obra, los profesores nos enfrentamos a unos estudiantes cuyo crecimiento estamos acompañando a veces a marcha forzada en contra de su interés por el asunto tratado en la clase. Posiblemente sea por esta razón que resulta una experiencia singular, estando en el presente, tratar de no estar en el presente sino en el pasado sin que el pasado sea una versión absurda y degradada de todo lo que tenemos, sabemos y podemos hacer hoy en día. Pero si finalmente lo es, si conocer el pasado no sirve más que para resaltar las virtudes del presente o sólo sirve para entender que una cosa es el presente y otra ese pasado del que estamos hablando, las herramientas de análisis que desplegaremos frente a esa situación serán seguramente las mismas porque se trata siempre de entender lo que alguien ha hecho en su clase un día o un año en particular. Es en este sentido que este artículo se hace eco de las posibilidades analíticas de estas posturas filosóficas respecto a la vez del pasado y de los modos en que lo "conocemos". Como herramientas de análisis que se enfocan tanto al discurso efectivo de la clase como al enfoque general de la historia que respalda la orientación del curso, las que provienen tanto de la historia intelectual como de la historia conceptual nos permiten claramente definir en qué lugar estamos respecto al uso de términos o a la interpretación de discursos provenientes del pasado.

Si como propone Palonen (1997) la propia filosofía de la historia -la de Koselleck incluida- puede ser analizada "conceptualmente" -o "intelectualmente" - también la historiografía y las clases de historia pueden serlo con esas mismas herramientas. El discurso de los historiadores, como el de los profesores, también tiene "contexto" -Michel de Certeau (1993, pp. 69 y ss.) hablaría más bien de lugar-. Los historiadores escriben o hablan dirigiéndose a alguien, real o imaginario, y lo que para ellos significan algunos

${ }^{24}$ Esta situación hizo de la historia intelectual skinnieriana un campo de inagotables polémicas, como puede verse en Tully (1989).

\section{()(1) $(3$}


términos no es lo mismo que para otros... de otro tiempo, de otra escuela, de otra orientación historiográfica o filosófica. Si pensamos en los trabajos traducidos, la dificultad podría volverse más y más compleja. Los profesores en general hablamos -y aún si escribimos- lo hacemos para personas de carne y hueso, con nombre y apellido, y casi nunca damos por descontado que todos van a entender eso que constituye el centro de nuestra clase. Desde este punto de vista la percepción de la fuerza ilocutoria del discurso de un profesor cuando expone, cuando pregunta o cuando dialoga con los estudiantes debería permitirnos -y más en primera persona del singular- ver más clara o más profundamente de qué se trata ese "texto". Si entendemos -siguiendo a Ricœur (2001) - a la acción como un texto, duplicamos el efecto de la herramienta. Finalmente, si hay algo dotado de una innegable fuerza ilocutoria es la producción estudiantil (artefactos y gestos). Dirigida muy especialmente a ese profesor que es el referente pero además es el evaluador, a menudo sólo se la entiende sabiendo lo que ha leído, lo que hablamos en clase, a la luz de algunas "intenciones" -siempre imaginadas, deducidas, supuestas- como por ejemplo que quiere mejorar la calificación u otras circunstancias particulares, tal vez en el sentido de llamar la atención de los compañeros o provocar el enojo del profesor.

Podemos por otra parte pensar en la interacción de los estudiantes con el vocabulario que les presentamos y sugerir una analogía "conceptual" con la forma en que los historiadores se relacionan con los textos antiguos. Para muchos estudiantes los profesores de historia hablamos en la lengua del pasado o los obligamos a leer en ella, aunque no haya de hecho ni palabras nuevas ni palabras difíciles. También es cierto que esperamos -relativamente-que escriban en ese registro y no en el de su oralidad cotidiana. Todos sabemos por ejemplo el trabajo que cuesta ayudar a los estudiantes a "decodificar" el sentido de "El espíritu de las leyes", porque ni el espíritu es espíritu, ni las leyes son estrictamente leyes... en el sentido que la palabra tiene para nosotros hoy en día. ${ }^{25}$ De la misma manera, muchas veces los estudiantes (o sus padres) nos hablan en una lengua "extraña" que contiene las mismas palabras que la nuestra pero que no se decodifica tan fácilmente y a menudo produce en el receptor una interpretación diferente a la que el emisor ha querido dar.

${ }^{25}$ También sabemos que en el pasado hubo personas que fueron agraciadas con suertes de estancia... lo que para algunos estudiantes quiere decir que "se habían sacado una estancia”. Véase Reglamento provisorio para el fomento de la campaña y seguridad de sus hacendados, 1815, en http://www.uc.org.uy/d1000c.htm

\section{()(1) $\$$}


Naturalmente esto no es hacer historia conceptual o intelectual del presente. Es con toda seguridad un asunto del que ha de ocuparse la didáctica de la historia en tanto teoría de la práctica de la enseñanza. Las herramientas para hacerlo, como siempre, provienen de campos muy diversos y son siempre bienvenidas.

\section{CONCLUSIÓN: EL PASADO EN EL PASADO Y EL PRESENTE EN EL PRESENTE}

Nunca se dirá suficientemente que los muertos, cuyo luto lleva la historia, han estado vivos.

Paul Ricœur

La enseñanza de la historia atraviesa en estos tiempos aguas inciertas y turbulentas. No habrá seguramente un lugar en el que no se sienta deudora de unos orígenes en los cuales los articuladores que la hicieron posible -es decir, la historiografía del siglo XIX y los noveles Estados-Nación- no estén presentes. Lo que sucede es que a estas alturas el hecho de que ambos han experimentado cambios notables es difícil de negar y por lo tanto hacer de cuenta que las cosas mejorarán restableciendo un equilibrio inicial que no conduce en realidad a ningún lado. De hecho la relación entre la historiografía (y también la filosofía de la historia) y el Estado, o la nación, o el Estado-nación ha dejado de ser tan armoniosa y obvia como lo era hace 100 años o más.

Es precisamente en este escenario que la enseñanza de la historia -ya sea que se la mire desde un lugar institucional y jerárquico o desde el aula de cada uno- experimenta sensaciones nuevas y desafiantes. Por otro lado, posiblemente nunca antes haya tenido a la mano tal cantidad y diversidad de herramientas de análisis para darle a la comprensión de la práctica de la enseñanza sentidos tan diversos y profundos como está hoy en día en condiciones de hacer. En este artículo me he limitado a indagar en la forma en que la filosofía de la historia contemporánea está en posición de suministrar una canasta de herramientas decididamente potentes a la hora de analizar las prácticas de enseñanza de la historia (y por práctica de la enseñanza entiendo no solamente el tiempo de aula, sino todo el cortejo de actividades que contribuyen a hacerlo posible, como los procesos de planificación, preparación de materiales, propuestas de ejercitación y evaluación, y obviamente,

\section{(1)(1)}


las tareas de análisis de esa práctica en formas diversas y siempre singulares). Hay, por supuesto, otros campos a los que apelar en busca de herramientas de análisis, como pueden ser la lingüística, la filosofía, la psicología -particularmente el psicoanálisis-, las distintas miradas antropológicas y también la propia historiografía.

Como hemos visto, sólo el hecho de que la historia (es decir la historiografía) se haya convertido explícitamente en la obra de un autor (Barthes, Certeau, White, Ricœur) es suficiente para alterar un escenario en el cual ya no es lo mismo dar "la república romana" que enfocarse en "lo que dice -por ejemplo- Homo acerca de la república romana”, a no ser que estemos limitados a informar a nuestros alumnos sobre hechos y acontecimientos, personajes, lugares, etc. Para decir que César fue asesinado en el año 44 a. C. no es necesario remitir específicamente a Homo o a cualquier otro historiador. Decir que tomamos, por ejemplo, a Homo porque es el que dice la verdad, tampoco ayuda. De hecho esta cuestión -como tantas otras en este mismo sentido- se desdobla en dos asuntos: el de ser un modo de entender los contenidos enseñados y el de convertir ese asunto en un contenido de enseñanza por sí mismo y entonces enseñar "lo que dice Homo" de la república romana y no solamente "lo que pasó".

Que la historiografía sea un trabajo de autor-como lo son por ejemplo las novelas- instala la cuestión en una dimensión temporal que articula el presente de la escritura con el pasado de los acontecimientos relatados (aun en el sentido de análisis, conceptualización, etc.). Si lo miramos aún más de cerca agregamos un segundo presente, el de la clase o el del curso que se vincula con el presente del historiador o de los historiadores articulando ambos a su vez con el pasado de las temáticas que por alguna razón abordamos en clase ese día. Podemos pensar en el futuro implicado en la cuestión -por ejemplo el de cumplir con el programa, o para los alumnos aprobar el curso, o al menos pasar las pruebas semestrales-y ampliamos la complejidad temporal que se abre ante nuestros ojos en una clase común, de un año cualquiera.

Un paso más, y el sentido de los contenidos cambian de color. ¿Tiene el mismo sentido estudiar la república romana para los italianos que para los europeos, para los estadunidenses o para los chinos? La puesta en evidencia de la dimensión eurocentrista de la historiografía "universal", acompañada por la emergencia de miradas alternativas para los sentidos, para los tiempos y para las conceptualizaciones invita en cierta forma a repensar el sentido de los cursos, de los contenidos, de los programas... donde uno puede rápidamente sacar la conclusión de que algo sobra y algo falta, o al menos de que

\section{()(1) $\$$}


algo abunda y algo escasea. Si además vivimos en el país de los subalternos, con más razón.

Por otra parte, algunas herramientas como las de la historia conceptual y las de la historia intelectual -sumadas a las del aparato hermenéutico y semiótico que las acompaña y que no es de su exclusividad- nos dan elementos para ver el presente de todos los días en los diálogos, en las preguntas, en los trabajos de los estudiantes como los historiadores acostumbran acercarse a los textos del pasado. De alguna manera nos dan la posibilidad de acompañar el gesto historiográfico de la asunción de la otredad del pasado, de su paseidad esencial, habilitándonos a comprender al otro del pasado como deberíamos hacerlo con todos los otros con los que convivimos. Nos permite, finalmente, sentirnos los otros del pasado, esos que los romanos nunca hubieran comprendido como nosotros lo hacemos. Nos permite también sentirnos otros de nuestros alumnos que a menudo ven las cosas "de otra manera", de esa que no es la que nosotros desearíamos.

Es entonces claro que en cierta forma las novedades de la historiografía y la filosofía de la historia pueden entrar en la clase sin demasiada violencia. Me interesa, sin embargo, destacar la manera en que esas herramientas aportan también al campo de la didáctica de la historia, entendida como la teoría de la práctica de la enseñanza (por cada uno) y no como un conjunto de recetas o de conceptualizaciones - precisamente- sobre lo que otros hacen. Desde este punto de vista, la interpretación es un componente transversal a toda la práctica: interpretación de la lectura (que contiene ya una interpretación) e interpretación del saber para ofrecerlo a los estudiantes; interpretación de sus producciones orales y escritas, que son una interpretación de lo que leyeron y escucharon en clase, interpretación de lo que hice en mi clase de ayer... Esto quiere decir antes que nada que los profesores hablamos de lo que sabemos porque lo leímos y no simplemente de lo que pasó. Los alumnos saben lo que el profesor dijo, o lo que le mandó leer, etc., en relación con lo que pasó. Si miramos estas afirmaciones desde el lugar de la historiografía, reproducen en espejo y hacia adelante la incertidumbre que la acompaña respecto del conocimiento del pasado. La idea de "fusión de horizontes" de Gadamer (1977, pp. 372-373) se expande con cada nuevo lector que ha fabricado un texto con base en su comprensión de la lectura, y esto cuenta para los profesores, y para los alumnos (y para los profesores que los leen o escuchan, evaluándolos).

Como hemos visto más arriba -y en un nivel análogo al que señala Koselleck en referencia a la temporalización de los conceptos- es ampliamente

\section{()(1) $\circledast$}


posible que muchos de nuestros alumnos nos escuchen o lean lo que les mandamos, como los historiadores se enfrentan a los documentos antiguos. Ellos tienen que hacer un esfuerzo por saber lo que muchas palabras que les son conocidas quieren decir para sus profesores de la misma manera que dialogar con ellos a veces da la sensación de que es más o menos como hablar con gente de otros tiempos. Tal vez los profesores más jóvenes lo sientan menos... En todo caso tenemos herramientas para enfrentarnos a todas las situaciones: leer documentos, leer libros, leer trabajos escolares, hablar con los alumnos... con sus padres... La cuestión es siempre la misma: volver pensable al otro sin que deje de serlo, porque todo el mundo es el otro de alguien en algún lugar, en algún tiempo y en alguna circunstancia.

\section{LISTA DE REFERENCIAS}

Barthes, R. (1987a). El discurso de la historia. En R. Barthes, El susurro del lenguaje, Más allá de la palabra y la escritura (pp. 173-177). Barcelona/Buenos Aires: Paidós.

Barthes, R. (1987b). El efecto de lo real. En R. Barthes, El susurro del lenguaje, Más allá de la palabra y la escritura (pp. 141-155). Barcelona/Buenos Aires: Paidós.

Carr, D., Dray, W., Geraets, T., Ouellet, F. y Watelet, H. (eds.) (1982). La philosophie de l'histoire et la pratique historienne d'aujourd'hui / Philosophy of history and contemporary historiography. Ottawa: Éditions de l'Université d'Ottawa/The University of Ottawa Press.

Certeau, M. de (1970). La possession de Loudun. París: Gallimard.

Certeau, M. de (1993). La escritura de la historia [1975]. México: Universidad Iberoamericana.

Certeau, M. de (2007). La historia, ciencia y ficción. En M. de Certeau, Historia y psicoanálisis (pp. 1-23). México: Universidad Iberoamericana.

Chakrabarty, D. (2007). Provincializing Europe. Princeton: Princeton University Press. Danto, A. (2007). Narration and knowledge. Nueva York: Columbia University Press.

Derrida, J. (1967). De la grammatologie. París: Minuit.

Donnelly, J. F. (1999). Schooling Heidegger. On being in teaching. Teaching and teacher education, 15, 933-949.

Gadamer, H.-G. (1977). Verdad y método. Barcelona: Sígueme.

Ginzburg, C. (1994). El queso y los gusanos [1976]. Barcelona: Atajos.

Ginzburg, C. (2008). Mitos, emblemas, indicios. Morfología e historia. Barcelona: Gedisa. Grondin, J. (2003). Le passage de l'herméneutique de Heidegger à celle de Gadamer. En J. Grondin, Le tournant herméneutique de la phénoménologie (pp. 57-83). París: PUf.

\section{()(1) $(9$}


Heidegger, M. (2000). Ontología. Hermenéutica de la facticidad. Madrid: Alianza.

Heidegger, M. (2002). Interpretaciones fenomenológicas sobre Aristóteles. (Indicación de la situación hermenéutica) [Informe Natorp]. Madrid: Trotta.

Koselleck, R. (1993). Futuro pasado. Para una semántica de los tiempos históricos. Barcelona: Paidós.

Koselleck, R. (2010). historia/Historia. Madrid: Trotta.

Lachabeaussière, A.-É.X. Poisson de (n. d.) Catéchisme républicain, philosophique et moral. Paris, An II de la République Française. Recuperado de http://gallica.bnf. fr/ark:/12148/bpt6k49090r/f2.item.zoom

Laville, Ch. (2000). La guerre des récits. Débats et illusions autour de l'enseignement de l'histoire. En H. Moniot y M. Serwanski, L'histoire et ses fonctions. Une pensée de des pratiques au présent (pp. 151-164). París: L’Harmattan.

Lowenthal, D. (1993). El pasado es un país extraño. Madrid: Akal.

Mallon, F. (2003). Campesinado y nación. La construcción de México y Perú postcoloniales. México: CiesAs/El Colegio de Michoacán/El Colegio de San Luis.

Mignolo, W. D. (2005). Espacios geográficos y localizaciones epistemológicas: la ratio entre la localización geográfica y subalternización de conocimientos. GEOgrafía, 7(13), 7-28.

Palonen, K. (1997). An application of conceptual history to itself. from method to theory in Reinhart Koselleck's Begriffsgeschichte. Finnish Yearbook of Political Thought, 1, 26-34.

Petit, J.-L. (2014). Ricœur et la théorie de l'action. Études Ricœuriennes/Ricœur Studies, 5(1), 142-151. DoI: 10.5195/errs.2014.214

Pouchepadas, J. (2000). Les subaltern Studies ou la critique postcoloniale de la modernité. L'homme, 156, 161-186. DoI: 10.4000/lhomme.75

Ricœur, P. (1996). Tiempo y narración, III. El tiempo narrado. Madrid: Siglo XXI.

Ricœur, P. (2001). La razón práctica. En P. Ricœur, Del texto a la acción. Madrid: Fondo de Cultura de España.

Ricœur, P. (2003). La memoria, la historia, el olvido. Madrid: Trotta.

Ricœur, P. (2004). Tiempo y narración, I. Configuración del tiempo en el relato histórico. Madrid: Siglo XXI.

Rüsen, J. (1989). The development of narrative competence in historical learning -an ontogenetic hypothesis concerning moral consciousness. History and Memory, 1(2), 35-59.

Rufer, M. (2009). Huellas errantes. Rumor, verdad e historia desde una crítica poscolonial de la razón. Versión, 23, 17-50.

Skinner, Q. (2000). Significado y comprensión en la historia de las ideas. Prismas. Revista de Historia Intelectual, 4, 149-191.

\section{()(1) $(2$}


Spivak, G. (1998). ¿Puede hablar el subalterno? Orbis Tertius, 3(6), 175-235.

Spivak, G. (2008). Deconstruyendo la historiografía. En S. Mezzadra et al., Estudios poscoloniales. Ensayos fundamentales (pp. 33-68). Madrid: Traficantes de Sueños.

Tully, J. (ed.). (1989). Meaning and context. Quentin Skinner and his critics. Princeton: Princeton University Press.

White, H. (1973). Metahistory. The historical imagination in nineteehth-century Europe. Baltimore/Londres: The Johns Hopkins University Press.

White, H. (1978). The historical text as a literary artifact. En H. White, Tropics of discourse. Essays in cultural criticism (pp. 81-100). Baltimore/Londres: The Johns Hopkins University Press.

White, H. (2008). The historical event. Brown University and differences: A Journal of Feminist Cultural Studies, 19(2), 9-34. DoI: 10.1215/10407391-2008-002

Wittgenstein, L. (1999). Investigaciones filosóficas. Barcelona: Atalaya.

Zavala, A. (julio-diciembre, 2013). La historia, la nación y después... Praxis Educativa, 8(2), 581-605. DoI: 10.5212/PraxEduc.v.8i2.00011

Zavala, A. (septiembre-diciembre, 2014). Para leer un manual de historia. Una mirada desde las herramientas de análisis. Secuencia, 90, 167-189. DoI: http://dx.doi. org/10.18234/secuencia.v0i90.1242 